\title{
ANALYSIS CONTENT OF ORGANIC MATTER IN SEDIMENT AND ABUNDANCE OF MACROZOOBENTHOS IN TELUK BUO PADANG WEST SUMATERA
}

\author{
Rinol Putra Utama ${ }^{1 *}$, Syahril Nedi $^{2}$, Afrizal Tanjung ${ }^{2}$ \\ ${ }^{1}$ Student of The Faculty of Fisheries and Marine Science University of Riau, Pekanbaru \\ ${ }^{2}$ Lecturer at The Faculty of Fisheries and Marine Science University of Riau, Pekanbaru \\ *rinol.putra69@gmail.com
}

\begin{abstract}
This research was conducted in May 2018 in the waters of Teluk Buo, Padang, West Sumatra. The purpose of this study was to determine the environmental quality of the Teluk Buo waters, especially to determine the abundance of macrozoobenthos and determine the relationship between sediment organic matter and abundance of macrozoobenthos. The method used in this study is a survey method. The results of the study note that the waters of the Teluk Buo are included in the medium polluted criteria with a diversity index $\left(\mathrm{H}^{\prime}\right)$ ranging from 2.18-3.43, dominance index (C) 0.10-0.32 and uniformity index (e) 0.51-0,78. Abundance ranges from $80-240 \mathrm{ind} / \mathrm{m}^{2}$ with the number of macrozoobenthos species found there are 9 species of gastropods and 5 species of bivalves. The relationship of sediment organic matter content to macrozoobenthos abundance was included in the moderate criteria with a correlation coefficient $(r)-0.382$.
\end{abstract}

Keywords: Organic materials, macrozoobenthos, sediments, Teluk Buo

\section{PENDAHULUAN}

Kawasan perairan Teluk Buo merupakan kawasan perairan di Sumatera Barat yang aktif dalam bidang pelabuhan barang dan pabrik pengolahan ikan serta pabrik semen. Aktivitas ini tentunya dapat mempengaruhi perairan di sekitar termasuk biota lautnya, baik epifauna maupun infaunanya. Aktivitas manusia bisa menjadi penyebab utama terjadinya pencemaran perairan karena menghasilkan material organik dan anorganik yang dapat mempengaruhi tingkat kesuburan perairan yang menyebabkan terganggunya keseimbangan organisme yang ada.

Menurut Edward (2003), bahan organik berasal dari perairan itu sendiri melalui proses penguraian, pelapukan dan dekomposisi tumbuh-tumbuhan, sisa-sisa organisme dan buangan limbah yang dengan adanya bakteri dapat diubah menjadi zat hara. Sisa senyawa bahan organik yang tidak dimanfaatkan oleh organisme permukaan lama-kelamaan akan mengendap ke dasar perairan sehingga partikel sedimen yang ada dalam perairan kaya akan zat hara baik yang berasal dari dekomposisi sedimen maupun senyawa yang berasal dari jasad flora dan fauna yang mati.

Banyaknya bahan organik di dalam perairan akan menyebabkan menurunnya kadar oksigen terlarut di dalam perairan dan jika keadaan ini berlangsung lama akan menyebabkan perairan menjadi anaerob, sehingga organisme yang hidup di dalam perairan tersebut akan mati (Marwan, 2013).

Salah satu organisme yang dapat terpengaruh adalah benthos karena 
organisme ini hidupnya menetap. Hewan benthos erat kaitannya dengan tersedianya bahan organik yang terkandung dalam substrat, karena bahan organik merupakan sumber nutrien bagi biota laut yang pada umumnya terdapat pada substrat dasar sehingga ketergantungannya terhadap bahan organik sangat besar.

Makrozoobenthos adalah organisme yang hidup menetap (sesile) dan memiliki daya adaptasi yang bervariasi terhadap lingkungan. Selain itu makrozoobenthos juga memegang peranan penting sebagai detritivor pada substrat sehingga dapat dijadikan indikator keseimbangan dalam suatu ekosistem. Ketersediaan bahan organik sedimen dapat memberikan variasi terhadap kelimpahan organisme yang ada. Berdasarkan hal tersebut maka penulis tertarik melakukan penelitian mengenai analisis kandungan bahan organik sedimen dan kelimpahan makrozoobenthos di Perairan Teluk Buo Bungus, Padang, Sumatera Barat.

Tujuan penelitian ini adalah untuk mengetahui kualitas lingkungan Perairan Teluk Buo, terutama untuk mengetahui kelimpahan makrozoobenthos serta hubungan antara bahan organik sedimen dengan kelimpahan makrozoobenthos

\section{METODE PENELITIAN Waktu dan Tempat}

Penelitian ini dilaksanakan pada bulan Mei 2018, pengambilan sampel dilakukan di perairan Teluk Buo, Bungus, Sumatera Barat. Analisis bahan organik dan makrozoobenthos dilakukan di Laboratorium Kimia Laut dan Laboratorium Biologi Laut Jurusan Ilmu Kelautan Fakultas Perikanan dan Kelautan Universitas Riau.

\section{Penentuan Lokasi Titik Sampling}

Perairan Teluk Buo dijadikan sebagai lokasi pengambilan sampel dimana metode yang digunakan dalam penentuan titik sampling dilakukan secara purposive. Penentuan lokasi sampling melalui beberapa pertimbangan dan juga kriteria kondisi perairan. Dilihat dari kondisi perairan lokasi tersebut peneliti ingin mengambil sampel di beberapa titik stasiun yang dapat diklasifikasikan sebagai berikut:

- Stasiun 1 : Terletak di kawasan mangrove

- Stasiun 2 : Terletak di kawasan industri dan pelabuhan, dan

- Stasiun 3 : Terletak di kawasan muara sungai dan pemukiman penduduk

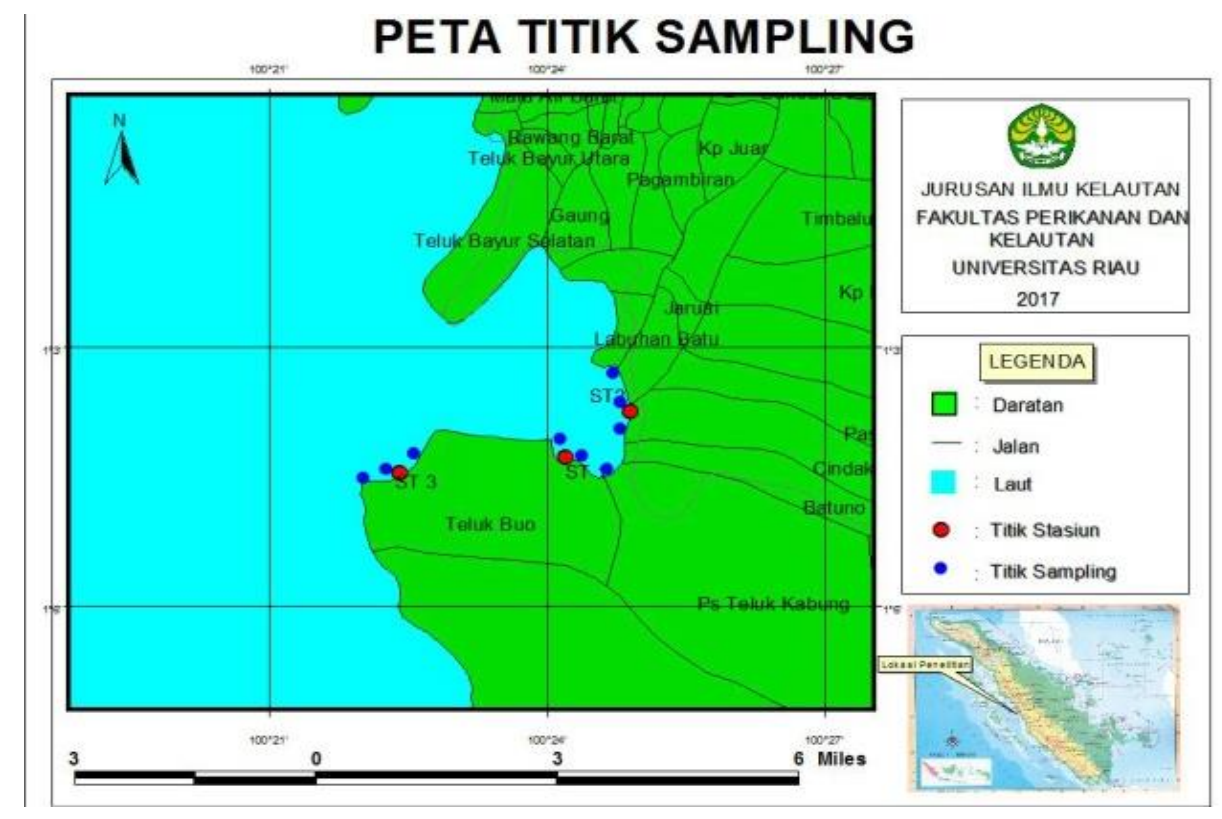

Gambar 1. Peta Lokasi Penelitian 


\section{Pengambilan Data Sampel}

Pengambilan sampel sedimen di lapangan dilakukan dengan menggunakan eckman grab atau grab sampler sebanyak 1000 gr di tiap titik stasiun. Sampel kemudian dipisahkan sebanyak 500 gr dan dimasukkan ke dalam kantong plastik yang sudah diberi label. 500 gr sampel lainnya diayak kemudian makrozoobenthos yang didapat diawetkan dan dimasukkan ke dalam plastik dan diberi label. Selanjutnya sampel dibawa ke laboratorium untuk dianalisis. Pengukuran parameter kualitas air meliputi: suhu, $\mathrm{pH}$, kecepatan arus, dan salinitas. Parameter ini diukur pada saat pengambilan sampel pada masing-masing titik sampling.

\section{Analisis Data}

Data tentang kelimpahan, keragaman, keseragaman jenis serta bahan organik dibahas secara deskriptif. Perbedaan antara stasiun untuk kelimpahan makrozoobenthos dan bahan organik sedimen di analisa menggunakan uji Anova dan dilanjutkan dengan uji lanjut LSD jika terdapat perbedaan antar stasiun, dengan demikian hipotesis 1 dapat dibuktikan. Analisis dilakukan dengan bantuan software
Microsoft Excel dan Statistical Package for Social Science (SPSS).

Selanjutnya untuk membuktikan hipotesis dua dapat digunakan analisis korelasi dan regresi (Tanjung, 2014). dengan model matematis sebagai berikut:

Keterangan:

$$
\mathbf{Y}=\mathbf{a}+\mathbf{b x}
$$

$\mathrm{Y}=$ Kelimpahan makrozoobenthos

$\mathrm{x}=$ Kandungan bahan organik

$\mathrm{a}=$ Konstanta

$\mathrm{b}=$ Koefisien kemiringan

Kekuatan hubungan dua variable secara kuantitatif dapat dibagi atas empat (Colton dalam Sabri dan Hastono, 2007), yaitu:

- 0,00-0,25: Hubungan lemah

- 0,26-0,50 : Hubungan sedang

- 0,51-0,75 : Hubungan kuat

- 0,76-1,00: Hubungan sangat kuat / sempurna

\section{HASIL DAN PEMBAHASAN \\ Parameter Kualitas Perairan}

Kualitas Perairan di Teluk Buo adalah sebagai berikut: $\mathrm{pH}$ berkisar 5,36,77, suhu $30,6-32,7{ }^{0} \mathrm{C}$, salinitas $29-31$ $\%$, dan kecepatan arus $0,08-0,1 \mathrm{~m} / \mathrm{s}$. Nilai parameter kualitas perairan secara keseluruhan disajikan pada Tabel 1.

Tabel 1. Parameter Kualitas Perairan Teluk Buo

\begin{tabular}{cccccc}
\hline Stasiun & T. Sampling & $\mathbf{p H}$ & Suhu $\left({ }^{\mathbf{0}} \mathbf{C}\right)$ & Salinitas $\left(\mathbf{\%}_{\mathbf{0}}\right)$ & Arus $(\mathbf{m} / \mathbf{s})$ \\
\hline \multirow{3}{*}{1} & 1 & 5,97 & 30,6 & 30 & 0,1111 \\
& 2 & 6,11 & 31,5 & 30 & 0,0833 \\
& 3 & 6,77 & 31,8 & 30 & 0,0952 \\
\hline \multirow{3}{*}{2} & 1 & 6,06 & 31,8 & 31 & 0,0526 \\
& 2 & 6,08 & 32,7 & 30 & 0,0625 \\
& 3 & 5,79 & 32,2 & 31 & 0,0690 \\
\hline \multirow{3}{*}{3} & 1 & 5,71 & 31,3 & 30 & 0,1000 \\
& 2 & 5,57 & 31,2 & 30 & 0,0601 \\
& 3 & 5,3 & 30,7 & 29 & 0,0633 \\
\hline
\end{tabular}

Kandungan Bahan Organik Sedimen Kandungan bahan organik Sedimen yang ditemukan di Perairan Teluk Buo Sumatera Barat dapat dilihat pada Tabel 2 
Tabel 2. Rata-rata Persentase Kandungan Bahan Organik Sedimen (\%) di Perairan Teluk Buo

\begin{tabular}{ccccc}
\hline \multirow{2}{*}{ Stasiun } & \multicolumn{3}{c}{ Titik Sampling } & \multirow{2}{*}{ Rata-rata (\%) } \\
\cline { 2 - 4 } & $\mathbf{1}$ & $\mathbf{2}$ & $\mathbf{3}$ & 10,81 \\
1 & 11,71 & 8,81 & 11,92 & 8,13 \\
2 & 11,80 & 8,22 & 4,37 & 25,31 \\
\hline
\end{tabular}

Seperti yang disajikan pada Tabel 2, Kandungan bahan organik di perairan Teluk Buo yaitu berkisar 4,37-28,83\% dengan rata-rata keseluruhan stasiun $14,75 \%$. Kandungan bahan organik tertinggi terdapat pada stasiun 3 dengan rata-rata $25,31 \%$. Pada stasiun 3 terdapat kawasan hutan mangrove yang menyebabkan kandungan bahan organik di dalam perairan meningkat karena serasah dari batang kayu dan daun mangrove yang berada di sekitar perairan tersebut memberikan sumbangan bahan organik ke dalam perairan. Selanjutnya stasiun 1 dengan kandungan bahan organik rata-rata 10,81\%. Pada stasiun 1 terdapat beberapa pabrik sehingga menyebabkan kandungan bahan organik yang dihasilkan oleh limbah pabrik-pabrik yang ada di sekitar perairan tersebut memberikan pengaruh terhadap kandungan organik di perairan.

Stasiun 2 merupakan stasiun dengan rata-rata bahan organik terendah di perairan
Teluk Buo sebesar 8,13\%. Hal ini disebabkan substrat dasar perairan wilayah ini didominasi oleh pasir. Dasar perairan berlumpur cenderung mengakumulasi bahan organik yang terbawa aliran air, dimana tekstur dan ukuran partikel yang halus memudahkan terserapnya bahan organik. Dari hasil uji menggunakan analisis Oneway Anova perbedaan kandungan bahan organik sedimen pada ketiga stasiun diperoleh adanya perbedaan sangat nyata, dan dari hasil uji lanjut LSD menunjukkan adanya perbedaan sangat nyata.

\section{Fraksi Sedimen}

Hasil analisis fraksi sedimen pada masing-masing stasiun di perairan Teluk Buo menunjukkan bahwa sedimen didominasi oleh fraksi lumpur. Persentase fraksi sedimen pada semua stasiun dapat dilihat pada Tabel 3 .

Tabel 3. Persentase Fraksi Sedimen di Perairan Teluk Buo

\begin{tabular}{|c|c|c|c|c|c|}
\hline \multirow{2}{*}{ Stasiun } & \multirow{2}{*}{$\begin{array}{c}\text { Titik } \\
\text { Sampling }\end{array}$} & \multicolumn{3}{|c|}{ Fraksi Sedimen (\%) } & \multirow{2}{*}{ Tipe Sedimen } \\
\hline & & Kerikil & Pasir & Lumpur & \\
\hline \multirow{3}{*}{1} & 1 & 11,08 & 11,95 & 76,97 & Lumpur \\
\hline & 2 & 0,31 & 25,94 & 73,75 & Lumpur Berpasir \\
\hline & 3 & 1,76 & 17,32 & 80,92 & Lumpur \\
\hline \multicolumn{2}{|c|}{ Rata-rata } & 4,38 & 18,40 & 77,21 & Lumpur Berpasir \\
\hline \multirow{3}{*}{2} & 1 & 1,01 & 16,15 & 82,84 & Lumpur \\
\hline & 2 & 1,33 & 40,73 & 57,94 & Lumpur Berpasir \\
\hline & 3 & 20,68 & 42,15 & 37,17 & Kerkil+Pasir+Lumpur \\
\hline \multicolumn{2}{|c|}{ Rata-rata } & 7,67 & 33,01 & 59,32 & Lumpur Berpasir \\
\hline \multirow{3}{*}{3} & 1 & 0,72 & 32,8 & 66,48 & Lumpur Berpasir \\
\hline & 2 & 1,06 & 12,32 & 86,62 & Lumpur \\
\hline & 3 & 2,51 & 11,2 & 86,29 & Lumpur \\
\hline \multicolumn{2}{|c|}{ Rata-rata } & 1,43 & 18,77 & 79,80 & Lumpur Berpasir \\
\hline
\end{tabular}


Fraksi sedimen dominan adalah lumpur dengan persentase $72,11 \%$ kemudian pasir $23,4 \%$ dan kerilil $4,5 \%$. Hal ini disebabkan karena wilayah perairan Teluk Buo merupakan kawasan yang berada di daerah teluk dengan gelombang dan kecepatan arusnya yang tenang, sehingga partikel sedimen yang berukuran halus akan bertahan dan menetap.

Data hasil untuk fraksi lumpur tertinggi terdapat pada titik sampling 3.2 yaitu 86,62\%. Stasiun 3 merupakan kawasan mangrove dimana arus dan gelombangnya tenang. Untuk fraksi pasir tertinggi terdapat pada titik sampling 2.3 dengan $41,15 \%$ dan untuk fraksi kerikil tertinggi terdapat pada stasiun 2.3 yaitu 20,68\%, dimana stasiun ini merupakan kawasan pemukiman penduduk yang arus dan gelombangnya relatif kuat. Hal ini sesuai dengan pendapat Rifardi (2012), arus dan gelombang merupakan faktor kekuatan utama yang menentukan arah dan sebaran sedimen. Kekuatan ini pula yang menyebabkan karakteristik sedimen berbeda sehingga pada dasar perairan disusun oleh berbagai kelompok populasi sedimen.

\section{Jenis dan Kelimpahan Makrozoobenthos}

Hasil pengamatan jenis makrozoobenthos diperoleh 2 kelas yaitu gastropoda dan bivalva. Berdasarkan hasil yang didapatkan gastropoda memiliki 9 jenis dan bivalva 5 jenis. Makrozoobenthos yang ditemukan dapat dilihat pada Tabel 4 .

Tabel 4. Jenis-jenis Markozoobenthos di Perairan Teluk Buo

\begin{tabular}{|c|c|c|c|}
\hline No & Filum & Kelas & Spesies \\
\hline 1 & \multirow{14}{*}{ Mollusca } & \multirow{9}{*}{ Gastropoda } & Circulus striatus \\
\hline 2 & & & Epitonium clathrus \\
\hline 3 & & & Atlanta echinogyra \\
\hline 4 & & & Littoria scabra \\
\hline 5 & & & Oenopota rufa \\
\hline 6 & & & Raphitoma purpurea \\
\hline 7 & & & Assiminea grayana \\
\hline 8 & & & Mangelia attenuata \\
\hline 9 & & & Turritella duplicata \\
\hline 10 & & \multirow{5}{*}{ Bivalva } & Abra prismatica \\
\hline 11 & & & Acanthocardia tuberculata \\
\hline 12 & & & Astarte elliptica \\
\hline 13 & & & Barbatia fusca \\
\hline 14 & & & Anadara granosa \\
\hline
\end{tabular}

Banyaknya gastropoda yang dijumpai pada perairan tersebut dikarenakan pada kelas gastropoda dapat beradaptasi dengan kondisi fisika perairan dengan berbagai macam arus dan gelombang, selain itu juga dikarenakan keberadaan organisme ini didukung oleh morfologi dan sifat hidup organisme ini. Gastropoda mempunyai kemampuan daya adaptasi yang lebih tinggi dari benthos lainnya, hal ini didukung oleh struktur tubuh yang bercangkang yang dapat memperkecil pengaruh hempasan ombak, dan sifat hidupnya yang menempel dan dapat menggali lubang pada substrat dimana mereka hidup.

Dari hasil analisis diperoleh kelimpahan makrozoobenthos di perairan Teluk Buo berkisar 80-240 ind $/ \mathrm{m}^{2}$. Kelimpahan makrozoobenthos tertinggi terdapat pada stasiun 2 dengan rata-rata $186,67 \mathrm{ind} / \mathrm{m}^{2}$, hal ini disebabkan karena fraksi sedimen dan substrat yang lebih beragam sehingga dapat mendukung lebih banyak keberlangsungan hidup 
makrozoobenthos. Sedangkan stasiun 3 merupakan stasiun dengan kelimpahan terendah yaitu $101,33 \mathrm{ind} / \mathrm{m}^{2}$. Hal ini disebabkan karena pada stasiun 3 didominasi oleh fraksi lumpur dan tingginya kandungan bahan organik, sehingga makrozoobenthos yang dapat beradaptasi di perairan tersebut lebih sedikit. Kepadatan suatu spesies juga dipengaruhi oleh beberapa faktor ekologi seperti kemampuan beradaptasi, substrat yang mendukung untuk hidup dan faktor alami lainnya.

\section{Indeks Keragaman (H'), Indeks Dominansi (C') dan Indeks Keseragaman (e)}

Hasil perhitungan rata-rata indeks keragaman jenis $\left(\mathrm{H}^{\prime}\right)$, indeks dominansi (C) dan indeks keseragaman (e) makroozobenthos di perairan Teluk Buo pada masing-masing stasiun dapat dilihat pada Tabel 5.

Tabel 5. Nilai Perhitungan Indeks Keragaman, Dominansi dan Keseragaman di Perairan Teluk Buo

\begin{tabular}{llll}
\hline Stasiun & Keragaman $\left(\mathbf{H}^{\prime}\right)$ & Dominansi $(\mathbf{C})$ & Keseragaman $(\mathbf{e})$ \\
\hline 1 & 3,43 & 0,10 & 0,78 \\
2 & 3,01 & 0,13 & 0,59 \\
3 & 2,18 & 0,32 & 0,51 \\
\hline
\end{tabular}

Berdasarkan Tabel 5, nilai indeks keragaman, indeks dominansi dan indeks keseragaman jenis menunjukkan bahwa keragaman jenis tertinggi berada pada Stasiun 1 dengan nilai 3,43. Kemudian nilai dominansi tertinggi berada pada stasiun 3 dengan nilai 0,32 dan nilai keseragaman tertinggi pada Stasiun 1 dengan nilai 0,78. Nilai H' dari seluruh stasiun berkisar 2,18 3,43 dimana nilai $H^{\prime}$ yang diperoleh lebih dari 3. Menurut kriteria penilaian berdasarkan petunjuk (Krebs dalam Purwaningsih, 2000) maka dapat digolongkan kondisi keragaman tinggi, dan lingkungan perairan belum mengalami gangguan. Nilai $H^{\prime}$ tertinggi terdapat di stasiun 1 yaitu 3,43. Hal ini dikarenakan kawasan ini berada di kawasan pabrik sehingga kondisi perairannya pun beragam. Sedangkan H' terendah terdapat pada stasiun 3 yaitu 2,18. Hal ini dikarenakan fraksi yang didominasi oleh lumpur dan tingginya kandungan bahan organik sehingga hanya beberapa jenis makrozoobenthos yang dapat hidup di perairan tersebut.

Nilai indeks dominansi (C') yang terdapat di perairan Teluk Buo berkisar 0,1 0,32 . Berdasarkan data tersebut diketahui bahwa C' mendekati nol yang berarti perairan tersebut tidak mengalami gangguan lingkunan karena tidak ada spesies yang dominan di perairan tersebut. Sependapat dengan Simpson dalam Siagian (2005), bahwa nilai C' berkisar $0-1$, dimana jika nilai $\mathrm{C}$ mendekati 0 berarti tidak ada dominansi jenis tertentu dan jika nilai $\mathrm{C}$ mendekati 1 berarti terjadi dominansi jenis tertentu. Astrini et al. (2014) menyatakan bahwa adanya dominansi jenis tertentu diduga karena lingkungan tersebut telah mengalami gangguan yang cukup serius sehingga hanya spesies tersebut yang dapat bertahan.

Hasil perhitungan nilai indeks keseragaman pada perairan Teluk Buo berkisar 0,51 - 0,78. Dari data tersebut dapat dilihat bahwa indeks keseragaman pada perairan tersebut mendekati 1 yang berarti perairan dianggap seimbang. Hal ini sependapat dengan Abdullah et al. (1989) yang menyatakan kriteria penilaian indeks keseragaman terletak antara 0 dan 1, bila nilai $\mathrm{e}=1$, berarti perairan dianggap seimbang sedangkan nilai e mendekati 0 dianggap teremar. Hartati dan Awaluddin (2007) menggambarkan bahwa semakin bersar nilai keseragaman menunjukkan keseragaman 
jenis yang besar. Artinya kepadatan jenis dapat dikatakan sama dan cenderung tidak dominansi oleh jenis tertentu. Sebaliknya semakin kecil nilai keseragaman menujukkan keseragaman jenis yang kecil, artinya kepadatan tiap jenis dapat dikatakan tidak sama dan cenderug didominasi oleh jenis tertentu.

\section{Hubungan Antara kandungan Bahan Organik Sedimen dengan Kelimpahan Makrozoobenthos}

Hasil analisis regresi linier sederhana antara kandungan bahan organik sedimen dengan kelimpahan makrozoobenthos di perairan Teluk Buo diperoleh persamaan regresi $\mathrm{Y}=-2,46 \mathrm{X}+173,56$ dengan koefisien determinasi (R2) sebesar 0,131 dan koefisien korelasi (r) -0,362. Artinya hubungan antara kandungan bahan organik dengan kelimpahan makrozoobenthos termasuk kriteria sedang. Hal ini sependapat dengan Colton dalam Sabri dan Hastono (2007) yang menyatakan bahwa jika nilai koefisien korelasi berada di antara 0,26-0,50 maka memiliki hubungan sedang. Berdasarkan regresi kandungan bahan organik dengan kelimpahan makrozoobenthos maka didapatkan hubungan negatif yaitu jika kandungan bahan organik meningkat maka kelimpahan makrozoobenthos akan menurun.

Menurut marwan (2013) makrozoobenthos erat kairannya dengan tersedianya bahan organik yang terkandung dalam substrat, karena bahan organik merupakan sumber nutrien bagi biota yang pada umumnya terdapat pada substrat dasar. Namun jika bahan organik melebihi ambang batas sewajarnya maka kedudukan bahan organik tersebut dianggap sebagai bahan pencemar.

Pengaruh bahan organik terhadap kelimpahan makrozoobenthos diperoleh dari nilai hasil uji regresi dengan nilai koefisien determinasi (R2) sebesar $13,1 \%$. Itu artinya $86,9 \%$ dipengaruhi faktor lingkungan lainnya meliputi fisika-kimia perairan seperti oksigen terlarut, kecepatan arus dan substrat dasar. APHA dalam Ulfah et al. (2012) menyatakan bahwa keberadaan hewan benthos pada suatu perairan sangat dipengaruhi oleh berbagai faktor lingkungan, baik biotik maupun abiotik. Faktor biotik yang berpengaruh diantaranya adalah produsen yang merupakan salah satu sumber makanan bagi hewan benthos. Adapun faktor abiotik adalah fisika-kimia air yang diantaranya suhu, arus, oksigen terlarut (DO), kebutuhan oksigen biologi (BOD) dan kimia (COD) serta kandungan nitrogen $(\mathrm{N})$, kedalaman air dan substrat dasar.

\section{KESIMPULAN DAN SARAN Kesimpulan}

Kondisi lingkungan perairan Teluk Buo relatif baik namun $\mathrm{pH}$ termasuk relatif asam dan tidak ideal untuk makrozoobenthos. Dari penelitian didapat nilai keanekaragaman makrozoobenthos yang berkisar $2,18-3,43$, keseragaman $0,51-0,78$ dan indeks dominansi $0,1-0,32$.

Jumlah spesies yang ditemukan terdiri atas 9 spesies gastropoda yaitu Circulus striatus, Epitonium clathrus, Atlanta echinogyra, Littoria scabra, Oenopota rufa, Raphitoma purpurea, Assiminea grayana, Mangelia attenuata dan Turritella duplicata sedangkan bivalva terdapat 5 spesies yaitu Abra prismatica, Acanthocardia tuberculata, Astarte elliptica, Barbatia fusca dan Anadara granosa dengan kelimpahan berkisar 80-240 ind $/ \mathrm{m}^{2}$.

Kandungan bahan organik sedimen pada tiap stasiun di perairan Teluk Buo berkisar 4,37-28,83. Rata-rata kandungan bahan organik sedimen tertinggi berada pada Stasiun 3 yaitu 25,31 sedangkan kandungan bahan organik sedimen terendah berada pada Stasiun 2 yaitu 8,13 .

Perbedaan kelimpahan makrozoobenthos pada ketiga stasiun memiliki nilai $\mathrm{P}>0,05$ yang menggambarkan perbedaan kelimpahan antar stasiun tidak berbeda nyata. Perbedaan kandungan bahan organik sedimen antar stasiun diperoleh $\mathrm{P}<0,01$ yang menggambarkan perbedaan kandungan bahan organik sedimen antar stasiun berbeda sangat nyata. 


\begin{abstract}
Pengaruh bahan organik sedimen terhadap kelimpahan makrozoobenthos sebesar $13,1 \%$ sedangkan $86,9 \%$ dipengaruhi oleh faktor lingkungan lainnya. Koefisien korelasi $(r)=-0,362$ yang berarti hubungan antara kandungan bahan organik dengan kelimpahan makrozoobenthos termasuk kriteria sedang.
\end{abstract}

\section{Saran}

Diharapkan untuk masyarakat sekitar
dan pemerintah setempat untuk tetap menjaga kawasan perairan agar organisme yang hidup diperairan tetap terjaga, serta diharapkan agar dilakukan penelitian lanjutan akan faktor lainnya yang diduga memiliki hubungan dengan komposisi sedimen dan kandungan bahan organik serta struktur komunitas makrozoobenthos pada perairan Teluk Buo agar hasil dari analisis data lebih terukur.

\section{DAFTAR PUSTAKA}

1. Abdullah, C,I,P., Sedana, Y., B. Sadjono, M. Ahmad, dan N.A. Emnur. (1989). Evaluasi Kualitas Fisika Kimia dan Biologi Air Sungai Siak di Sekitar PT. Indah Kiat Pulp Perawang, Riau. J. PUSLIT UR Volume (2): Pages 1-2

2. Arifin, B. (2008). Karakteristik Sedimen Ditinjau dari Aktivitas Anthropogenik di Perairan Dumai. Skripsi. Fakultas Perikanan dan Kelautan Universitas Riau, Pekanbaru.

3. Barus, T. A. 2001. Pengantar Limnologi Studi tentang Ekosistem Sungai dan Danau. Program Studi Biologi USU FMIPA, Medan.

4. Dahuri, R., J. Rais, S. G. Putra, M. J. Sitepu. (2001). Pengelolaan Sumberdaya Wilayah Pesisir dan Lautan secara Terpadu. Praditya Pranata. Jakarta.

5. Effendi, H. (2007). Kualitas Air Bagi Pengelolaan Sumberdaya dan Lingkungan Perairan. Kanisius. Jakarta.

6. Gosner, K, L. (1971). Guide to Identification of Marine and Estuarine Invertebrates. New Jersey.

7. Hardjowigeno, S. (1989). Mangrove Soils of Indonesia, dalam Prosiding Seminar Simposium Mangrove Management its Ecological and Economic Consideration. Bogor.

8. Jati, W, N. (2003). Studi Komparasi Keanekaragaman Benthos di Wadu Sempor, Waduk Kedungombo dan Waduk Gajah Mungkur Jawa Tengah. Yogyakarta: Fakultas Biologi Universitas Atmaja.

9. Lalli, C, M., T. R. Parsons. (1993). Biological Oceanography and Introduction. Persamon Press. New York.

10. Marwan. (2013). Kandungan Bahan Organik Sedimen dan Makrozoobenthos sebagai Indikator Pencemaran Perairan Pantai Tanjung Uban Kepulauan Riau. Skripsi, Fakultas Perikanan dan Kelautan Universitas Riau, Pekanbaru.

11. Nontji, A. (2007). Laut Nusantara. Edisi revisi cetakan kelima. Djambatan. Jakarta.

12. Nybakken. (1992). Biologi Laut Suatu Pendekatan Ekologis. Diterjemahkan oleh H. M. Eidman., D. Koesobiono, G. Bengen., M. Hutomo dan S. Seokarjo. PT. Gramedia, Jakarta.

13. Odum, E, P. (1993). Dasar-Dasar Ekologi (Fundamental of Ecology). Diterjemahkan oleh T. J. Samingan. Gajah Mada university Press, Jakarta.

14. Prihatiningsih. (2004). Struktur Komunitas Makrozoobenthos di Perairan Teluk Jakarta. Skripsi, Institut Pertanian Bogor, Bogor.

15. Purwaningsih, Y. (2000). Studi Makrozoobenthos sebagai Tolak Ukur Pencemaran Minyak P.T. Kondur. Skripsi, Fakultas Perikanan dan Kelautan Universitas Riau, Pekanbaru

16. Rifardi. (2001). Study on Sedimentology from the Sungai Mesjid Estuary and its Environs in the Rupat Sirait, the East Coast of Sumatera Island. Journal of Coastal Development. Riset Universitas Diponegoro. 
17. Rifardi. (2008). Tekstur Sampling dan Analisis Sedimen. Universitas Riau Press, Pekanbaru 18. Rifardi. (2012). Ekologi Sedimen Laut Modern Edisi Revisi. Universitas Riau Press, Pekanbaru

19. Setiawan, D. (2008). Struktur Komunitas Makrozoobenthos sebagai Bioindikator Kualitas Lingkungan Perairan HIlir Sungai Musi. Tesis, Sekolah Pasca Sarjana IPB, Bogor

20. Siagian, M. (2005). Diktat Kuliah Ekologi Perairan. Fakultas Perikanan dan Kelautan Universitas Riau, Pekanbaru.

21. Sinaga, T. (2009). Keanekaragaman Makrozoobenthos sebagai Indikator Kualitas Perairan Danau Toba Balige Kabupaten Toba Samosir. Tesis, USU, Medan

22. Sudjana. (1996). Metode Statistika. Tarsito, Bandung

23. Supriharyono. (2007). Konservasi Ekosistem Sumberdaya Hayati. Pustaka Belajar, Yogyakarta

24. Tanjung, A., (1995). Distribusi Makrozoobenthos di Zona Intertidal Selat Morong Kabupaten Bengkalis Riau. Pusat Penelitian UR, Pekanbaru

25. Tanjung, A. (2014). Rancangan Percobaan Edisi Revisi. Tantaramesta, Bandung

26. Zulkifli, H., Z, Hanafiah., D, A, Puspitawati. (2009). Struktur dan Fungsi Komunitas Makrozoobenthos di Perairan Sungai Musi Kota Palembang. Telaah Indikator Pencemaran Air. Skripsi,Jurusan FMIPA. Universitas Sriwijaya 